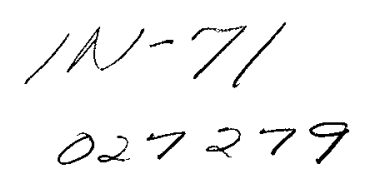

NASA Technical Memorandum 107458

AIAA-97-1641

\title{
Active Noise Control of Low Speed Fan Rotor-Stator Modes
}

Daniel L. Sutliff

AYT Corporation

Brook Park, Ohio

Ziqiang $\mathrm{Hu}$ and Frederic G. Pla

General Electric Corporate Research

and Development Center

Schenectady, New York

Laurence J. Heidelberg

Lewis Research Center

Cleveland, Ohio

Prepared for the

3rd Aeroacoustic Conference

cosponsored by the American Institute of Aeronautics and Astronautics

and the Confederation of European Aerospace Societies

Atlanta, Georgia, May 12-14, 1997

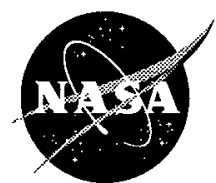

National Aeronautics and

Space Administration 


\section{-}




\title{
ACTIVE NOISE CONTROL OF LOW SPEED FAN ROTOR-STATOR MODES
}

\author{
Daniel L. Sutliff* \\ AYT Corporation \\ Brook Park, Ohio 44142 \\ Ziqiang $\mathrm{Hu}$ and Frederic G. Pla* \\ General Electric Corporate Research and Development Center \\ Schenectady, New York 12301 \\ Laurence J. Heidelberg* \\ National Aeronautics and Space Administration \\ Lewis Research Center \\ Cleveland, Ohio 44135
}

\begin{abstract}
$\underline{\text { Abstract }}$
This report describes the Active Noise Cancellation System designed by General Electric and tested in the NASA Lewis Research Center's 48 inch Active Noise Control Fan. The goal of this study was to assess the feasibility of using wall mounted secondary acoustic sources and sensors within the duct of a high bypass turbofan aircraft engine for active noise cancellation of fan tones. The control system is based on a modal control approach. A known acoustic mode propagating in the fan duct is canceled using an array of flush-mounted compact sound sources. Controller inputs are signals from a shaft encoder and a microphone array which senses the residual acoustic mode in the duct. The canceling modal signal is generated by a modal controller.
\end{abstract}

The key results are that the $(6,0)$ mode was completely eliminated at $920 \mathrm{~Hz}$ and substantially reduced elsewhere. The total tone power was reduced $9.4 \mathrm{~dB}$. Farfield 2BPF SPL reductions of $13 \mathrm{~dB}$ were obtained. The $(4,0)$ and $(4,1)$ modes were reduced simultaneously yielding a $15 \mathrm{~dB}$ modal PWL decrease. Global attenuation of PWL was obtained using an actuator and sensor system totally contained within the duct.

\section{Introduction}

A goal of the NASA Advanced Subsonic Technology Noise Reduction Program is the reduction in transport aircraft EPNL by $6 \mathrm{~dB}$ relative to 1992 technology. A component of EPNL is fan tone noise caused by rotorstator interaction and duct modal propagation. ${ }^{1}$

Theoretical and experimental work has shown that Active Noise Control (ANC) can significantly reduce the tone levels of ducted fans. NASA Lewis Research Center's (LeRC) Active Noise Control Fan (ANCF) serves as a test bed to verify proposed ANC technologies. ${ }^{2,3}$

A unique characteristic of turbomachinery noise is the modal structure. The acoustic waveform is threedimensional and highly complex, and is best described as a spinning mode. Knowledge of these spinning modes is important to identify the generation mechanism and to successfully apply noise control. Previous work ${ }^{4}$ has shown the potential for modal control to reduce the tone levels of ducted fans.

This report describes the Active Noise Cancellation System designed by General Electric (GE) and tested in the NASA Lewis Research Center's 48 inch Active Noise Control Fan. The goal of this study is to assess the feasibility of using wall mounted secondary acoustic sources and sensors within the duct of a high bypass turbofan aircraft engine for active noise cancellation of fan tones.

The GE ANC system is based on a modal control approach. A known acoustic mode propagating in the fan duct is canceled using an array of flush-mounted compact sound sources. The canceling modal signal is generated by a modal controller. Inputs to the controller are signals

*Senior Member, AIAA.

"This paper is declared a work of the U.S. Government and is not subject to copyright protection in the United States."

NASA TM-107458 
from a shaft encoder and from a microphone array which senses the residual acoustic mode in the duct.

The NASA ANCF facility uses a 16-bladed variablepitch rotor and can be configured with stator vanes to provide specific mode generation and propagation for active noise control research. A unique feature on the ANCF is the direct attachment of the rotor centerbody to the rig support column, eliminating the need for struts, which could contaminate acoustic measurements. Additionally, an Inflow Control Device (ICD) allows for static testing. The combination of low tip speed $(\sim 400 \mathrm{ft} / \mathrm{sec})$ and the 48 in. diameter produces fan tones of the same frequencies produced by full size advanced engines. Figure 1 shows a schematic of the ANCF. The parameters describing the NASA fan configuration used for this test are given below in Table I.

\section{TABLE I}

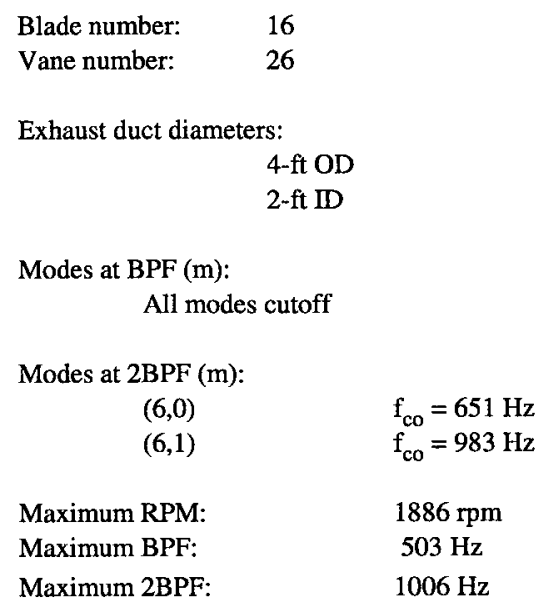

The fan configuration was chosen such that no modes are cut-on at the Blade Passage Frequency (BPF). The $(6,0)$ mode is cut-on when the fan RPM reaches 64.8 percent of the maximum speed. The $1053 \mathrm{~Hz}$ cut-on frequency for the second radial mode $(6,1)$ is outside the maximum RPM range of the test plan.

The target rpm for this system was chosen to correspond to a 2BPF tone of $935 \mathrm{~Hz}$. The system was designed to operate with a bandwidth of at least 10 percent.

\section{Actuator Array Design and Implementation}

\section{Acoustic Array Design}

A simulation tool based on a closed-form analytical simulation has been developed by R.E. Kraft ${ }^{5,6}$ at GE Aircraft Engines to determine the acoustic modes generated by an $\mathrm{N}$-element ring source in a cylindrical duct. This simulation was used to design the acoustic array. The simulation decomposes the sound field generated by a ring source into its individual modal components. It assumes the ring source is composed of a number of "piston-like" individual sources. Inputs to the simulation are the numberof actuators on the ring source, the mode to be generated, and source solidity (area of source divided by total ring area). Results are given in terms of the energy in the mode to be excited as well as the spillover energy into undesired higher order modes. The goal of the acoustic array design was toreach acompromise configuration which minimizes:

- Number and solidity of the actuator elements,

- Spillover into uncontrolled higher-order modes,

- Energy required by the actuator.

Several configurations were evaluated for the $m=6$ mode. Results for 24 source combinations are shown in Ref. 5 . The conclusion from this reference is that in order to maximize the acoustic energy in the $\mathrm{m}=6$ mode and minimize the spillover, the number of actuator elements must be maximized and the and the solidity must be minimized. Solidity is the most important factor in the range of parameters considered.

Practically, for high solidity (greater than 0.50 ), increasing the number of actuator elements does not increase the array effectiveness significantly. For low solidity (lower than 0.5 ), increasing the number of actuators significantly increases the effectiveness of the array by increasing the energy into the $m=6$ mode and reducing the spillover.

The actuator configuration chosen for this work had 16 actuators and a solidity equal to 0.25 . This represents a good compromise between performance and array complexity and size of each element. The main array characteristics are given in Table II.

\section{TABLE II}

$\begin{array}{ll}\text { First two modes generated: } & 6,-10 \\ \text { Circumferential length: } & 7.086 " \\ & (16.9 \%) \\ \text { Energy in } \mathrm{m}=6 \text { mode: } & 29.4 \% \\ \text { Energy in } \mathrm{m}=6 / \mathrm{m}=-10: & 1.68 \\ & \end{array}$

\section{Array Element Design}

The results of the array design were used as the basis for a preliminary design of the individual array elements. Each array element consists of a plate radiator mounted in a frame. The plate radiator is excited by a Piezoceramic (PZT) thin plate bonded to the plate radiator. The plate radiator is designed ${ }^{7}$ so that the resonance frequency of its first mode corresponds to the design frequency of $935 \mathrm{~Hz}$. 
Analytical models and experimental data were used to estimate the width, thickness, and material of the plate radiator required for a 7.086 in. length and a first-mode resonance frequency of $935 \mathrm{~Hz}$. Two design iterations were conducted. The final plate design consists of a $0.080 \mathrm{in}$. thick aluminum plate of dimensions 7.008 -in. by 4.488 -in .

The plate radiators are mounted in a 0.50 -in. thick aluminum frame and clamped using a 22-hole bolt pattern torqued to $100 \mathrm{in}$-lb. A series of tests were conducted to investigate variations in resonance frequency for different radiator plates and various assembly processes. Four pairs of plate radiators and PZT actuators were used. Variations in resonance frequency and amplitude were limited to $6 \mathrm{~Hz}$ and $1 \mathrm{~dB}$, respectively. Damping ratio variations were also small.

A 5 percent variation in the plate first mode resonance frequency, with no significant change in damping ratio and a $20 \mathrm{~Hz}, 3-\mathrm{dB}$ bandwidth was obtained using a variable clamping force on the frame and the use of (1) $1 / 8$-in. compliant gaskets on each side of the plate (2) 1/16-in. gaskets, and (3) bare frame (no gaskets).

An rpm bandwidth of at least 10 percent was desireable. To increase the bandwith the damping ratio was increased. A commercial structural damping material was also tested to fine tune plate radiators and control their damping. Damping layer thicknesses of $1 / 2$-in. by 2 -in. and 1 -in. by 2 -in. were tested. The damping ratios for untreated, 1/2-in. by 2 -in. treated, and 1 -in. by 2 -in. treated plates were 1.1, 1.5 and 2.2 percent, respectively. The first mode resonance frequency decreased from 907 to 854 to $807 \mathrm{~Hz}$ with increasing damping ratio due to the increasing mass loading.

Finally, it was shown that the electric circuit driving the PZT actuator (amplifier and matching circuits) affects the resonance frequency of the assembly by as much as 5 percent for the design used in this study. This shows that it is feasible to tune the actuator resonance frequency and damping by adjusting the impedance of the matching circuit.

It was concluded that the addition of damping material was the most effective and simple way to tune plate radiators and control their damping for this program. A 1 -in. by 2 -in. external damping layer was applied to all the plate radiators which raised their damping factor from an average of about 0.5 percent to $\sim 2$ percent.

Long term reliability testing for the plate radiator/ PZT actuator combination was conducted. The plate radiator was run successfully for $340 \mathrm{hr}$ at a sound pres- sure level of $130 \mathrm{~dB}$ (PZT actuator driven at $80 \mathrm{Vrms}$ ), and for $170 \mathrm{hr}$ at $134 \mathrm{~dB}$ measured $50.8 \mathrm{~mm}$ away from the center of the diaphragm. Figure 2 shows a diagram of the final array element configuration.

\section{Modal Control Algorithm}

\section{Modal Control Strategy}

A modal control strategy was developed at GE CRD for the active control of fan noise. This approach has the potential to be simpler than the time-or frequency-domain approaches. It allows each acoustic mode propagating in the fan duct to be controlled yielding a much better control over the far-field noise radiation than the standard time- or frequency-domain approaches.

The basic principle is as follows. The composite primary and canceling sound field is sensed by an array of error sensors located in the engine duct. A modal decomposition is performed using a spatial Fourier transform to extract the amplitude and phase of each mode to be canceled. This signal is then used to adjust the amplitude and phase of each "canceling mode" using an LMS algorithm. An inverse spatial Fourier transform is then performed on the "canceling mode" signal to generate the canceling signals for each individual canceling source.

One of the advantage of the modal approach is its simplicity and its ability to control modes individually. This approach blends the effectiveness of existing control algorithms with the physical understanding of duct acoustics to provide an efficient and simple control scheme. The controller size is independent of the number of error sensors and canceling sources since it is reduced to a set of independent single-input, single-output controllers - one for each mode to be canceled.

This approach considerably reduces the complexity of the controller compared to conventional time-domain or frequency domain control schemes. Increased resolution can be achieved by simply increasing the number of sensors and actuators. As with the time- and frequencydomain approaches, one critical element is the ability of the sensors and actuators to maintain known phase and amplitude characteristics. This requires on-line or off-line actuator and sensor system identification to be performed depending on their amplitude and phase stability.

The controller design was performed assuming the following design variables and assumptions:

- The fan duct is annular,

- The primary noise source is tonal and due to rotor/ stator interactions, 
- One mode at one frequency must be canceled,

- A 16-source circumferential array of wall-mounted plate radiators is used as the canceling source,

- Error sensing is performed with a circumferential microphone array,

- A tachometer signal is available as a frequency reference signal,

- Primary (fan) and secondary (canceling array) sources do not affect each other,

- Only one circumferential mode is cut-on in the frequency range of interest,

- Sound propagation in the duct is linear,

- Little sound reflection at the duct opening.

These assumptions are appropriate to full-scale turbofan engines with the exception of the number of modes.

\section{Modal Control Concept}

The fan noise is generated by interactions between rotor blades and stator vanes. The primary noise is tonal and propagates upstream and downstream of the fan duct in the form of circumferential and radial modes. For the purpose of this work, only circumferential modes are considered. For a given fan rotational speed $\Omega(s)$ (s is the Laplace variable) and duct geometry, the modal composition of the sound field is well known.

This information is used by the controller to generate a canceling sound field using an array of secondary sources. The total noise $\mathrm{E}(\mathrm{q}, \mathrm{s})$ ( $\mathrm{q}$ is the circumferential angle) in the mode of interest (mode $m$ ) at the microphone array is equal to the sum of the primary fan noise $D(q, s)$ and the secondary canceling noise $\mathrm{Y}(\mathrm{q}, \mathrm{s})$ for that mode. The goal of the control system is to adjust the amplitude and phase of the mode generated by the secondary sources in order to minimize the amplitude of mode $\mathrm{m}$ in the duct.

\section{Modal Control Algorithm}

The primary and secondary acoustic fields can be represented as shown in Fig. 3. The complex vector response at each microphone can be expressed by using the matrix representation given by:

$$
\mathbf{e}=\mathbf{d}+\mathbf{C y}
$$

where the complex vectors $\mathrm{e}, \mathrm{d}$, and $\mathrm{y}$ are defined as error signals, microphone inputs with primary source operating alone, and inputs to the secondary sources, respectively. The complex matrix $\mathrm{C}$ represents the transfer functions from the input to the secondary sources to the output of the microphone array system.
A cost function can be defined as the sum of the squared moduli of the outputs from all the error microphones:

$$
\mathbf{J}=\sum_{l=1}^{\mathrm{N}}\left|e_{l}\right|^{2}=\mathbf{e}^{\mathrm{H}} \mathbf{e}
$$

By minimizing the cost function $\mathrm{J}$ with respect to $\mathrm{y}$, we obtain:

$$
\mathbf{y}_{0}=-\left(\mathbf{C}^{\mathrm{H}} \mathbf{C}\right)^{-1} \mathbf{C}^{\mathrm{H}} \mathbf{d}
$$

Although the exact least squares solution discussed above is available, there are a number of practical problems associated with its direct computation in a practical control system. Iterative algorithms have been found to be very effective in solving this problem. The best known algorithm of this type is the Gauss-Newton method. Newton's method provides a very direct convergence to the exact least squares solution. However, if the problem is ill-conditioned the exact least squares solution can, in some cases, involve excessively large signals driving the secondary sources. The problem can be alleviated by introducing an "effort" term and a "rate" term in the cost function as follows.

$$
\begin{aligned}
\mathbf{J}_{\mathrm{d}}(\mathrm{k})=[\mathbf{e}(\mathrm{k}) & \left.-\mathbf{e}_{\mathrm{des}}\right]^{\mathrm{H}}\left[\mathbf{e}(\mathrm{k})-\mathbf{e}_{\mathrm{des}}\right] \\
& +\lambda_{1} \mathbf{y}^{\mathrm{H}}(\mathrm{k}) \mathbf{y}(\mathrm{k})+\lambda_{2} \Delta \mathbf{y}^{\mathrm{H}}(\mathrm{k}) \Delta \mathbf{y}(\mathrm{k})
\end{aligned}
$$

The three terms in Eq. (4) are generally called the "error" term, the "effort" term and the "rate" term. In the case where the number of secondary sources is the same as the number of error sensors, the matrix $\mathrm{C}$ is square and for this cost function thus becomes:

$$
\begin{array}{r}
y(k)=\left(-\mu \lambda_{1}\right) y(k-1)-\mu \lambda_{2}[y(k-1)-y(k-2)] \\
-\mu C^{-1}\left[\mathbf{e}(k-1)-\mathbf{e}_{\text {des }}\right]
\end{array}
$$

The variables in equations 4 and 5 are defined as follows: $\mathbf{y}(k)$ and $\mathbf{e}(\mathbf{k})$ are the vector of signals to the secondary sources and the error signal vector, respectively at the kth iteration; $m$ is the step size; $\mathbf{e}_{\text {des }}$ is a set of desired error outputs; $\lambda_{1}$ is a weighting coefficient for the control signals and has the effect of preventing small reductions at the error sensors at the expense of large control signals; $e_{2}$ is a weighting coefficient that penalizes large changes in 
the control variables which can sometimes have a destabilizing effect on iterative algorithms.

\section{Modal solution}

Let us define a spatial modal vector as:

$$
V_{m}=\frac{1}{\sqrt{N}}\left\{\begin{array}{c}
1 \\
e^{j\left(\frac{2 \pi m}{n}\right)} \\
e^{j\left(\frac{2 \pi m}{n}\right)(N-1)}
\end{array}\right\}
$$

where $\mathrm{m}$ is the circumferential mode order and $\mathrm{N}$ is the number of actuators and sensors evenly positioned around the duct. The spatial modal vectors $V$ are orthogonal and satisfy the following relationship:

$$
\mathbf{V}_{l}^{\mathrm{H}} \mathbf{V}_{\mathrm{m}}=\left\{\begin{array}{ll}
0 & \text { for } \mathrm{l} \neq \mathrm{m} \\
1 & \text { for } 1=\mathrm{m}
\end{array}\right\}
$$

where 1 and $\mathrm{m}$ are integers smaller than $\mathrm{N}$.

The output vector from the microphone array in the duct can be written as a summation of several modes. Since the primary goal is to control one single circumferential mode $(m=6)$, the output from the controller to the actuator can be expressed as:

$$
y(k)=y_{M}(k) V_{M}
$$

where $y_{M}(k)$ is a complex number representing the modal controller output at the kth iteration.

In Newton's algorithm, the system transfer function $\mathrm{C}$ has to be provided to update the input to the actuators. The easiest way to measure the transfer function is to send a signal to the actuators and to measure the microphone outputs without the primary noise sources. The transfer function can be easily calculated as:

$$
\mathbf{C}=\mathbf{x}_{\mathrm{cal}} / \mathbf{y}_{\mathrm{cal}}=\left(\mathrm{x}_{\mathrm{cal}} / \mathrm{y}_{\mathrm{cal}}\right) \frac{\mathbf{V}_{\mathrm{M}}}{\mathbf{V}_{\mathrm{M}}^{\prime}}=\mathrm{C}_{\mathrm{M}} \mathbf{V}_{\mathrm{M}} \mathbf{V}_{\mathrm{M}}^{\mathrm{H}}
$$

where $C_{M}=x_{c a l} / y_{c a l}$ is mth modal transfer function coefficient. Its inverse is given as

$$
\mathbf{C}^{-1}=\mathbf{y}_{\text {cal }} / \mathbf{x}_{\mathrm{cal}}=\left(1 / \mathrm{C}_{\mathrm{M}}\right) \mathbf{V}_{\mathrm{M}} \mathbf{V}_{\mathrm{M}}^{\mathrm{H}}=\mathrm{C}_{\mathrm{M}}^{-1} \mathbf{V}_{\mathrm{M}} \mathbf{V}_{\mathrm{M}}^{\mathrm{H}}(10)
$$

By multiplying both sides of Eq. (5) by the modal vector $\mathbf{V}_{M}$, we get:

$$
\begin{aligned}
\mathbf{V}_{M}^{\mathrm{H}} \mathbf{y}(\mathrm{k}) & =\left(1-\mu \lambda_{1}\right) \mathbf{V}_{\mathrm{M}}^{\mathrm{H}} \mathbf{y}(\mathrm{k}-1)-\mu \lambda_{2} \mathbf{V}_{\mathrm{M}}^{\mathrm{H}}[\mathbf{y}(\mathrm{k}-1) \\
& -\mathbf{y}(\mathrm{k}-2)]=\mu \mathbf{V}_{\mathrm{M}}^{\mathrm{H}} \mathbf{C}^{-1}\left[\mathbf{e}(\mathrm{k}-1)-\mathbf{e}_{\mathrm{des}}\right]
\end{aligned}
$$

The above vector equation can be simplified to the following scalar equation:

$$
\begin{aligned}
\mathrm{y}_{M}(\mathrm{k})= & \left(1-\mu \lambda_{1}\right) \mathrm{y}_{M}(\mathrm{k}-1)-\mu \lambda_{2}[\mathrm{y}(\mathrm{k}-1) \\
& -\mathrm{y}(\mathrm{k}-2)]=\mu \mathrm{C}_{\mathrm{M}}^{-1}\left[\mathrm{e}_{\mathrm{M}}(\mathrm{k}-1)-\mathrm{e}_{\mathrm{des} M}\right]
\end{aligned}
$$

\section{Sensor and Actuator Calibration}

Any difference among the actuator channels (both in amplitude and phase) must be compensated for since we want to generate a single spatial mode from the actuator array. These differences can be caused by differences between the actuator mechanical and electronic elements.

The exact modal information needs to be extracted from the sensor array, any difference (magnitude and phase) among sensor input channels also has to be compensated for. These differences can be caused by differences between sensors and/or sensor electronics (all the way to the controller digital input). The responses and gains of the sensors can be assumed to be linear and not to change during the test period allowing the sensor calibration to be conducted off-line.

Time-domain averaging is used in the data acquisition process to minimize the effect of broadband noise. Time-domain averaging is possible since the test signal is periodic and stationary, and because the signal generation and acquisition processes are synchronized to the blade passage frequency through a shaft encoder (synchronous sampling).

\section{Controller hardware/software implementation}

Figure 4 shows a block diagram of the system integration on the ANCF.

The controller hardware includes an industrial rack mount 486-DX2-66 PC, a Motorola DSP96002 signal processing board, a 32-channel ADC input board, and a 16-channel DAC output board. The software was implemented in C, and the 96000 Assembly language. The software has a user-friendly, menu-driven interface which allows the easy setup of important control parameters such as the m-order of the mode to be canceled, convergence constants. The user can also operate the system either in a 
manual or an automatic mode and start the various calibration procedures from the menu interface. Live displays of individual signals, modal signals, and performance indexes are available for use during the testing process.

The speed of rotation of the shaft is obtained using an optical encoder. The encoder signal is used to generate a "frame signal" at the 2BPF (around $1 \mathrm{kHz}$ ) which is used as an absolute frame reference and to initialize the controller. A sampling signal at 4 times $2 B P F$ is derived from the frame signal using an off the shelf frequency multiplier in order to synchronously trigger the data input and output processes.

A custom-designed I/O signal conditioning box was used for this test. It includes 16 inputs for the microphone array, 16 inputs for the feedback sensors on the array elements, and 16 outputs for the canceling array. The $\mathrm{I} / \mathrm{O}$ box performs the following functions:

- 32-input microphone signal conditioning including on all channels: microphone preamplifier and power supply, 0 to $40 \mathrm{~dB}$ adjustable gain, and active 4-pole lowpass and high-pass filters programmable using plug-in resistor packs.

- 16-output array element signal conditioning including on all channels: adjustable gain and active 4-pole low-pass reconstruction filter programmable using plug-in resistor packs.

Additional specifications include: SNR greater than $48 \mathrm{~dB}$, cross-talk less than $-48 \mathrm{~dB}$, and Common Mode Rejection Ratio (CMRR) greater than $80 \mathrm{~dB}$, test-channel output with dial-in channel selector, connector for ribbon cable to I/O boards in the ANC controller.

The amplifier array consists of 8 stereo audio amplifiers with custom step-up transformers and impedance matching inductors to drive the PZT elements.

\section{System Integration}

\section{Actuator Array Integration}

The actuator array was mounted on a 12 -in. long spool section of the NASA fan duct. Flats were machined on the spool to mount each array element. Each element was resiliently mounted on the ring using a 4-bolt pattern torqued to $30 \mathrm{in}$.-lb for easy mounting and removal.

Testing was performed to determine the amount of structure-borne cross-talk between actuators. Initial results showed an unacceptably high amount of cross-talk $(-10 \mathrm{~dB})$ between adjacent actuators primarily as a result of the matching resonances between actuators, the low damping of the diaphragms, and the low resiliency of the initial mounting technique. The problem was resolved by doubling the thickness of the vibration isolation gasket, putting a tygon jacket around each mounting screw, and using vibration absorbers between the actuator frame and the mounting bolt.

A 30-mil perforated steel plate was cut to dimension to fit into a 30-mil 53/16-in. groove machined inside the ring spool by NASA. The perforated plate ensures smooth flow over the actuators and provides additional protection for the actuators.

The feedback microphone array was implemented using 16 off the shelf Knolls microphones with custom signal conditioning circuits similar to the microphones used in the NASA Fan rotating rake measurement system. Calibration showed that the microphone response was accurate up to $135 \mathrm{~dB}$ with fairly flat amplitude and phase response over the frequency range of interest. Each microphone in the 16-microphone array was packaged in a porous shell adapter which was flush mounted in the NASA fan ring.

A microphone/canceling source calibrator was designed and fabricated. The calibrator is used to perform amplitude and phase calibration of each microphone and canceling source up to a frequency of $3 \mathrm{kHz}$ using a Shroeder calibration sequence. The calibrator consists of a plastic housing with a circular piezoceramic bender element generating the calibration acoustic signal and separating the calibrator in two chambers.

The calibration process was designed to compensate the amplitude and phase differences among 16 input sensor and 16 output channels. The calibration process was implemented in the following way:

1. Calibrate the feedback microphones in the back chambers of the actuators.

A calibration signal was sent to each actuator from the controller to drive the actuator in the selected frequency range. A transfer function was measured between every feedback microphone and the microphone inside the calibrator (as a reference). Each feedback microphone input was multiplied by the inverse of its transfer function to compensate for the phase and amplitude differences among all channels.

2. Calibrate the actuators using the feedback microphones. 
A calibration signal was sent to each actuator from the controller to drive the actuator in the selected frequency range. A transfer function was measured between the calibration signal (as a reference) and each feedback microphone input (microphone sensitivity and phase was compensated). Each actuator output was multiplied by the inverse of its transfer function to compensate for the phase and amplitude differences among all channels during controller operation.

\section{Calibrate the input sensors.}

A calibration signal was sent to the calibrator from the controller to drive each actuator in the selected frequency range. A transfer function was measured between the control microphone and the microphone inside the calibrator (as a reference). Each feedback microphone input was multiplied by the inverse of its transfer function to compensate for the phase and amplitude differences among all channels during controller operation.

The speaker calibration process was initially designed to compensate for actuator sensitivity and phase variation among all channels for both on-line and off-line operation. This procedure was instituted when it was observed that actuator sensitivity varied with different input levels for an initially selected PZT material. A feedback sensor was designed to monitor the sensitivity change during operation and to allow on-line compensation. It was found that actuator non-linearity was not an issue when using the final selection for PZT material, and, combined with the difficulty of implementing on-line calibration within the tight test schedule, it was decided not to implement on-line calibration in the software, and the calibration was accomplished off-line as described above.

The first resonance frequency of the piezoceramic bender element is around $900 \mathrm{~Hz}$. It can be driven by an audio amplifier or directly from a signal generator. A reference microphone is mounted in the front calibration chamber facing the opening. An O-ring on the chamber opening allows airtight contact between the calibration chamber and the sensor or actuator being calibrated. Tests conducted with an instrumentation microphone showed that the transfer function (both magnitude and phase) between the reference microphone and the calibration microphone was flat up to around $3 \mathrm{kHz}$.

\section{$\underline{\text { Results }}$}

\section{Test Bed}

The GE ANC Modal Control System was tested installed in the NASA Lewis Research Center's 48 inch ANCF facility. ${ }^{2,3}$ The primary measurement device on the ANCF is the Rotating Rake. The Rotating Rake is an implementation of a technique originally conceived by T.G. Sofrin ${ }^{8}$ whereby a rake containing radially distributed pressure transducers rotates in the circumferential direction at a precise fraction of the fan rotational speed. Each circumferential acoustic mode is known to rotate at a unique frequency ${ }^{5}$ in the rotor reference frame so that a Doppler shift is induced in the rake reference frame. Further reduction of the data into radial modes is accomplished through a least squares curve fit ${ }^{9}$.

The ANCF is located in the NASA LeRC's Aeroacoustic Propulsion Laboratory ${ }^{10}$ (AAPL), a hemispherical anechoic (to $125 \mathrm{~Hz}$ ), test facility. Farfield measurements are taken from 28 microphones at a radius of $50 \mathrm{ft}$ in the ANCF horizontal plane. The SPL data from these microphones are corrected to $40 \mathrm{ft}$, standard day conditions.

\section{Test Conditions}

The test of the GE ANC system occurred over the period of July to September 1995 . The primary ANCRing configuration was the exhaust installation. The primary ANCF configuration was 26 vanes with a blade pitch of 50 percent. The spacing between the rotor trailing edge and the stator leading edge, measured at the hub, was $2.25 \mathrm{in}$. The system was tested over a fan corrected rpm range of 1585 to 1804 . With 16 blades and 26 vanes, the $B P F$ is cutoff over this range.

At $2 \mathrm{BPF}$, in the exhaust, the $(6,0)$ mode begins to propagate at 1222 corrected rpm and the $(6,1)$ mode propagates at and above 1845 corrected rpm. Therefore, in the target configuration, only a single mode propagates over the range tested. The ANC control system was designed to target the $2 \mathrm{BPF}$ tone and thus operated over a frequency range of 860 to $980 \mathrm{~Hz}$. Secondary studies were done with the ANC ring installed in the inlet.

In addition, one study was done with the ring in the exhaust, with 28 stator vanes, over a fan corrected rpm range of 1481 to 1704 . At $2 \mathrm{BPF}$ the $(4,0)$ and $(4,1)$ modes are cut-on. This was beyond the design criteria of this ANC system but was done to investigate the possibilities of controlling higher order radials. It is realized that achieving acceptable results in control of two radials with a single ring actuator requires proper phasing between the fan generated radials.

\section{Data Summary}

Reduced data obtained with the rotating rake are presented in the following figures. A data point was taken 
at a given rpm with the control on, followed by a data point with the control off.

The control off and control on power levels in the $(6,0)$ mode versus corrected rpm are shown in Fig. 5(a) for the exhaust. The general control off levels are around $114 \mathrm{~dB}$ PWL, dropping to $107 \mathrm{~dB}$ PWL at $1800 \mathrm{rpm}$. A reduction of at least $15 \mathrm{~dB}$ occurs over the entire rpm range tested. The results are particularly outstanding around $1700 \mathrm{rpm}(920 \mathrm{~Hz})$, with 25 to $30 \mathrm{~dB}$ PWL reduction. This implies cancellation of the entire mode.

Figure 5(b) shows the results are again excellent around $920 \mathrm{~Hz}$ with the ANC ring installed in the inlet. Complete cancellation of the mode occurs. Above $1720 \mathrm{rpm}$ the transducer output reached the maximum safe output allowed for this test and therefore the optimum reduction could not be achieved.

The 2BPF total tone power (PWL) reduction is shown in Fig. 6. The total tone power is the sum of the power of all modes in a given harmonic. The maximum possible PWL reduction can be obtained by mathematically eliminating the $(6,0)$ mode from the control off modal decomposition. This is also shown on Fig. 6. A general trend of 4 to $8 \mathrm{~dB}$ total PWL reduction, with a maximum of $9 \mathrm{~dB}$ reduction is seen in the exhaust. This is out of a possible $14 \mathrm{~dB}$. The single run taken with the ANC ring in the inlet shows 2 to $4 \mathrm{~dB}$ reduction. As reported in the baseline studies for this fan, 2,3 the 11-segmented ICD generates a strong $\mathrm{m}=-1$ mode in the inlet. This limits the amount of total reduction obtainable in the inlet, about 8 to $12 \mathrm{~dB}$ PWL.

Mode power structure obtained from the rotating rake is plotted in three-dimensional bar graph format with circumferential mode index along one horizontal axis, radial mode index along the other, and mode PWL as bar height. Along the back wall the total power in each circumferential mode is shown. The control off mode structure is presented in Fig. 7(a). This is the acoustic characteristic of the fan at $2 \mathrm{BPF}$. Ideally, the only mode that would exist is the $(6,0)$ due to rotor stator interaction, but, typically, neighboring modes are also excited, perhaps due to spacing or to blade-to-blade imperfections. Also, other physical obstructions can cause periodic flow disturbances which generate modes.

An example is the ICD (Inflow Control Device) which excites the $\mathrm{m}=-1$ mode. The total tone power at 2BPF of $113.0 \mathrm{~dB}$ is the sum of each circumferential mode. This mode is not very large, but its contribution limits the PWL reduction that can be obtained by eliminating the $(6,0)$ mode. If the $(6,0)$ mode were totally elimi- nated, the remaining power would be $101.4 \mathrm{~dB}$. This means the maximum reduction possible is $11.6 \mathrm{~dB}$ PWL.

The same format is shown in Fig. 7(b) with the ANC system operating. The $(6,0)$ mode has been completely eliminated, a $30 \mathrm{~dB}$ SPL reduction. There are small increases in a few of the other modes. The total power is $104.2 \mathrm{~dB}$, a $8.8 \mathrm{~dB}$ PWL reduction out of a possible $11.6 \mathrm{~dB}$.

Figure 8(a) shows the mode structure of a similar control off case. The $(6,0)$ mode and the noise floor are comparable to the case shown in Fig. 7(a). The control on results are not as favorable, as seen in Fig. 8(b). The $(6,0)$ mode while greatly reduced, has a small remnant. A larger problem is the more numerous and larger spillover modes. The total PWL reduction is $4.4 \mathrm{~dB}$, not as high as the previous case.

A database of the complete mode structure was obtained and analyzed for each point. The amount of reduction achieved at a given configuration varied. These two cases were chosen to represent the results. The higher levels of reduction occur when the modal spillover is low, as in Fig. 7. Higher spillover prevented full realization of the reduction in some runs, as seen in Fig. 8. The severity of spillover varied with calibrations (system identification). In particular, the transfer function of the feedback microphones in the back chambers of the actuator exhibited variation.

The modal structure generated by ANC system with the fan off is presented in Fig. 9. The outputs of the transducers were higher than during the standard runs, in this case $119 \mathrm{~dB}$ PWL. The spillover modes are generally down 20 to $30 \mathrm{~dB}$ or more. The sum of the spillover modal power is $10 \mathrm{~dB}$ below the total PWL. In a sense, this is the signal-to-noise ratio of the ANC system.

The farfield data confirm the reduction. A typical control on/off directivity comparison is shown in Fig. 10. A $13 \mathrm{~dB}$ SPL reduction occurs in the $(6,0)$ mode lobe at 125 percent. The ANC ring is installed in the aft and therefore only SPL data from 90 to 180 percent are relevant. Integrating these two curves would yield a $2.0 \mathrm{~dB}$ PWL reduction. However great care must be taken with this number as the integration may not be accurate due to azimuthal variations in SPL directivity that can occur when multiple mode levels are present.

Although not designed to cancel other than spinning modes with only a single radial, the ANC system was operated to cancel the $\mathrm{m}=4$ mode, which is generated when 28 stator vanes are installed in the rig. Up to $15 \mathrm{~dB}$ 
PWL reduction occurs in the total $\mathrm{m}=4$ mode power level as shown in Fig. 11(a).

At $m=4,2$ radials are cut-on, the $(4,0)$ and $(4,1)$. The $(4,1)$ cuts-on just below 1480 rpm. Figure 11(b) shows cancellation occurs in both radials over the rpm range tested. The transducers can minimize only the wall pressure, which in this case is the superposition of the $(4,0)$ and $(4,1)$ wall pressure. This is a function of spacing between all components of the system, since the phase speed varies with the cutoff ratio.

Figures 12(a) and (b) show a typical mode power map for the 28 vane control off and on cases. At this frequency the $(4,0)$ is completely eliminated and $(4,1)$ is reduced $9 \mathrm{~dB}$. Spillover also occurs, limiting the total PWL reduction to $2.0 \mathrm{~dB}$ out of a possible $10.8 \mathrm{~dB}$.

\section{Conclusions and Recommendations}

An active noise cancellation concept for a highbypass turbofan was demonstrated. The system is based on a ring of flush mounted sources and a modal control approach. All sensors are contained within the fan duct.

The design condition (single radial) key results are that the $(6,0)$ was completely eliminated at the $920 \mathrm{~Hz}$ design frequency and substantially reduced over a 15 percent speed range. The total tone power was reduced $9.4 \mathrm{~dB}$ (out of a possible $14 \mathrm{~dB}$ ) (SPL) were obtained. Farfield reductions in the mode 6 lobe of $13 \mathrm{~dB}$ (SPL) occurred. The results indicate that global attenuation of PWL at the target frequency was obtained in the aft quadrant using an ANC actuator and sensor system totally contained within the duct.

A fan configuration with two radials present, which was beyond the design condition, was tested. The $(4,0)$ and $(4,1)$ modes were reduced simultaneously, yielding a $15 \mathrm{~dB}$ PWL decrease. The reduction in $\mathrm{m}=4$ occurred over a 12 percent rpm range. This system was not designed to reduce multiple radials, but good results were obtained. Further investigation may determine the limits extending a system of this type to multiple radials.

The quality of the results depended on precise mode generation. High spillover into spurious modes generated by the ANC actuator array caused less than optimum levels of PWL reduction. The variation in spillover is believed to be due to the actuator calibration procedure, but must be confirmed in subsequent tests. Another possibility is structure-borne cross-talk between actuators. Further investigation of the cause of spurious mode spillover is recommended, particularly as this might impact the accuracy requirements of the ANC actuator calibration and stability requirements of continuous operation.

Continuation of the development of an integrated analytical simulation that can be used to model the fan noise source and propagation, the coupling of the ANC actuators to the duct, the control system sensor signal pickup, and the control system algorithm data processing, is recommended. Incorporation of the effects of passive treatment into this simulation will further enhance its value as a design and evaluation tool in future studies.

In this study, ANC suppression was demonstrated for a single cut-on radial mode at the target spinning mode order. In order to develop ANC systems that will find eventual practical application in an aircraft engine fan duct, it will be necessary to tackle the problem of multiple cut-on radial modes in future efforts. The ability to under specify the number of circumferential actuator rings required to reduce multiple radials may be indicated by this study.

\section{Acknowledgments}

The authors would like to acknowledge the contributions of Scott Sommerfeldt and Yong-Cheol Park (of Penn State University at the time of this contract) to the development of the control system algorithm, software, and hardware.

\section{$\underline{\text { References }}$}

1. Tyler J.M., and Sofrin T.G., "Axial Flow Compressor Noise Studies," SAE Transactions, Vol. 70, 1962, pp. 309-332.

2. Heidelberg, L.H., Hall, D.G., Bridges, J.E., and Nallasamy, M., "Ducted Fan Test Bed for Active Noise Control and Aeroacoustics Research", NASA TM-107213, May 1996, also AIAA Paper 96-1740 May 1996.

3. Sutliff, D.L., Nallasamy, M., Heidelberg, L.J., and Elliott, D.M, "Baseline Acoustic Levels of the NASA Active Noise Control Fan Rig", NASA TM-107214, May 1996, also AIAA-96-1745, May 1996.

4. Sutliff, D.L., and Nagel, R.T.,"'Active Control of Farfield Noise from a Ducted Propeller," AIAA Journal, Vol. 33, No. 2, February 1995, pp. 231-236.

5. Kraft R.E. and Kontos K. B., "Theoretical Implications of Active Noise Control for Turbofan Engines," AIAA Paper 93-4355, Oct. 1993. 
6. Kraft, R.E., "Active Control of Fan Noise: Feasibility Study. Vol. 6: Theoretical Analysis for Coupling of Active Noise Control Actuator Ring Sources to an Annular Duct with Flow," NASA CR-198514, September 1996.

7. Pla, F.G. and Rajiyah H., "Active Control of Fan Noise - Feasibility Study. Vol. 2: Canceling Noise Source Design of an Acoustic Plate Radiator Using Piezoceramic Actuators," NASA CR-195440, March 1995.

8. Cicon, D.E., Sofrin, T.G., and Mathews, D.C., "Investigation of Continuously Traversing Microphone System for Mode Measurement," NASA CR-16804, Nov. 1982.
9. Hall, D.G., Heidelberg, L., and Konno, K., "Acoustic Mode Measurements in the Inlet of a Model Turbofan using a Continuously Rotating Rake:Data Collection/ Analysis Techniques," NASA TM-105963, Jan. 1993; also AIAA Paper 93-0599, Jan. 1993.

10. Cooper, B.A., "A Large Hemi-Anechoic Chamber Enclosure for Community-Compatible Aeroacoustic Testing of Aircraft Propulsion Systems," Journal of the Institute of Noise Control Engineering of the USA, Jan/Feb 1994. 


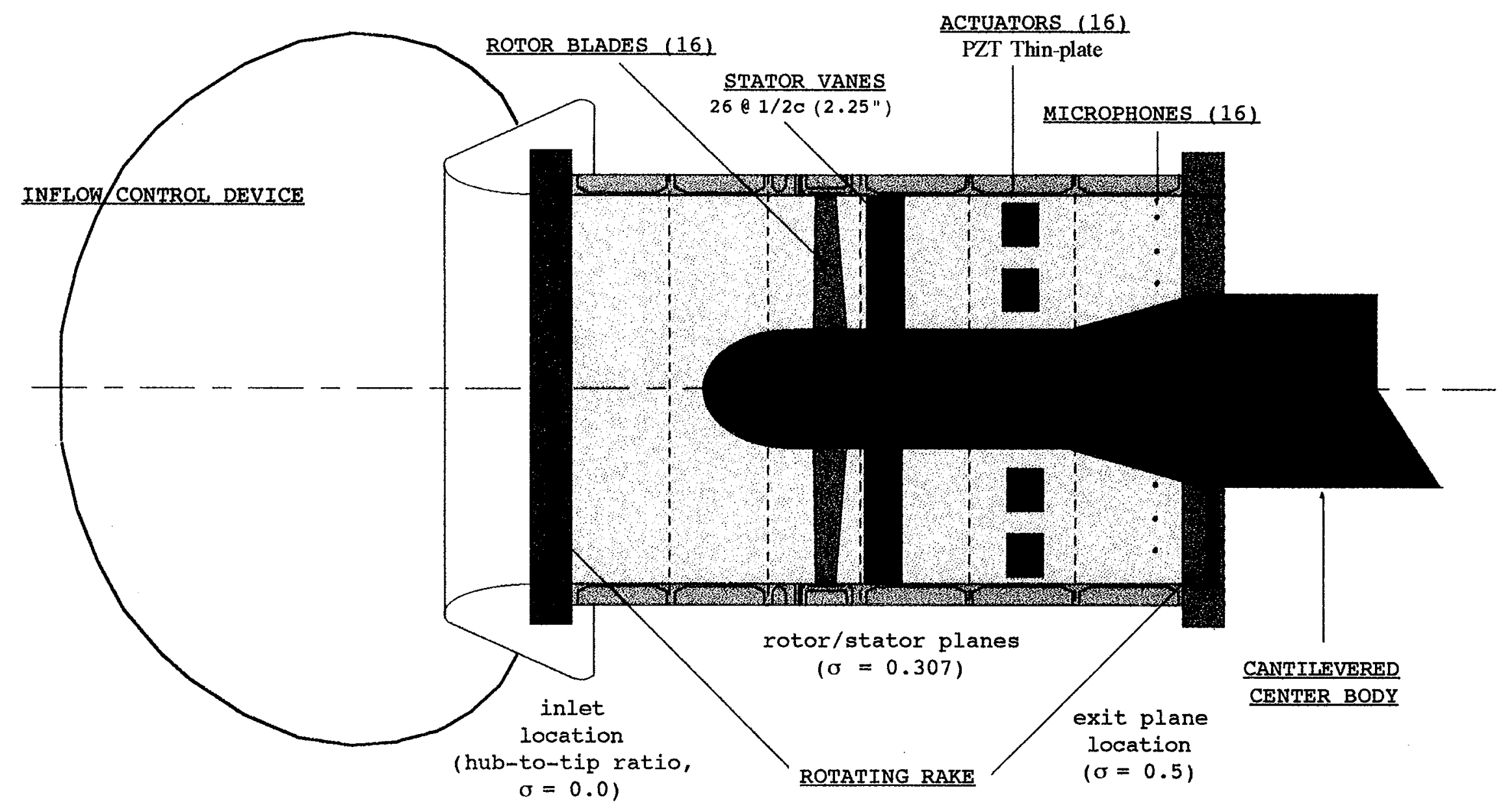

48" diameter fan

overall inlet \& exhaust ducts $1 / d=1$

FIGURE 1. Schematic of Active Noise Control Fan showing GE ANC Installation. 


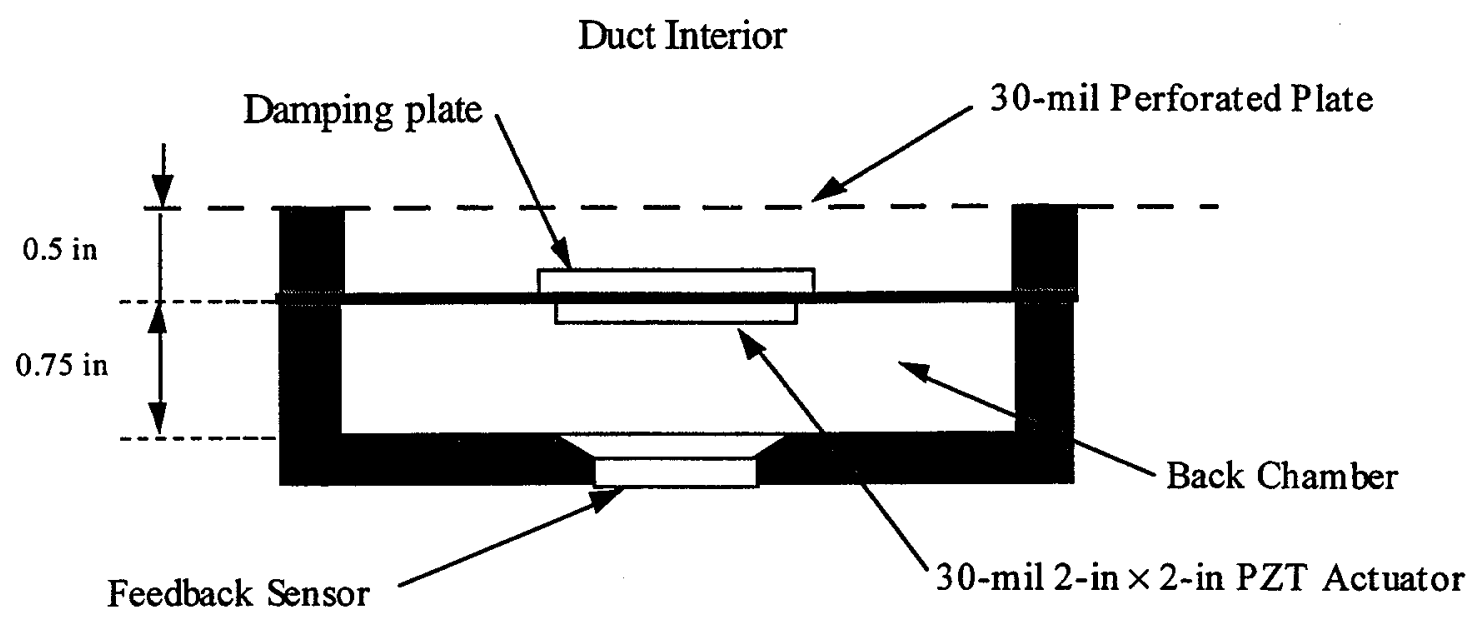

a) Element Schematic

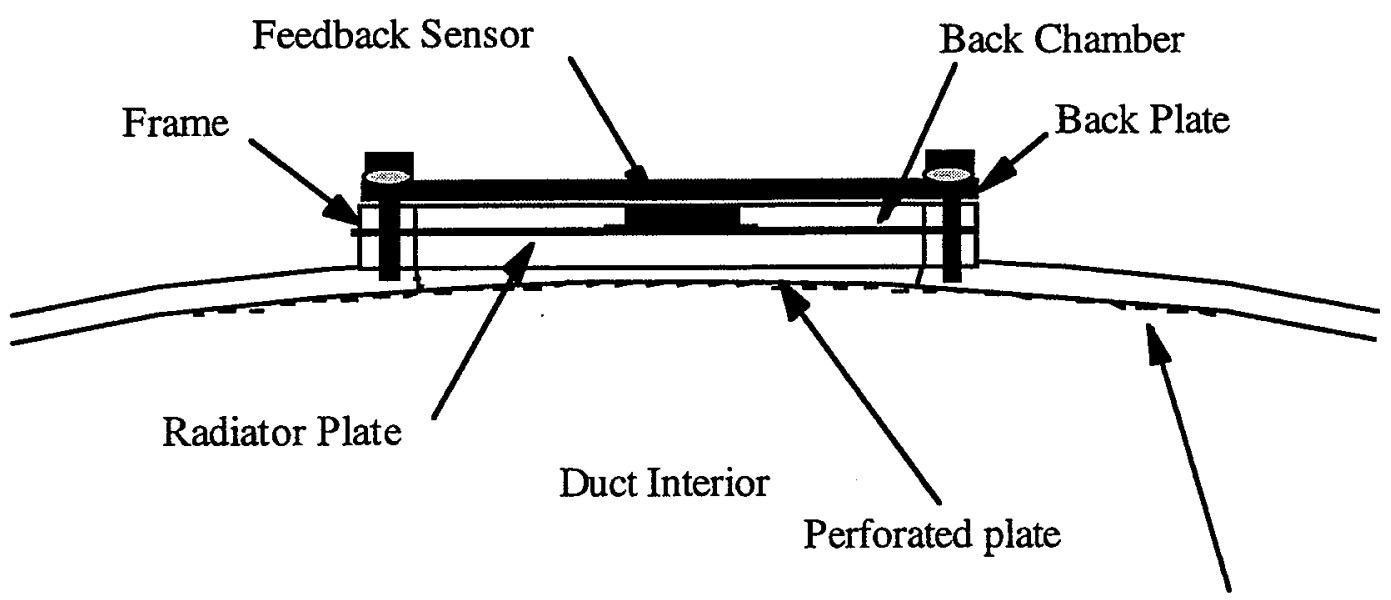

Ring Structure

b) Installation Schematic

FIGURE 2. Ring Element Actuator 


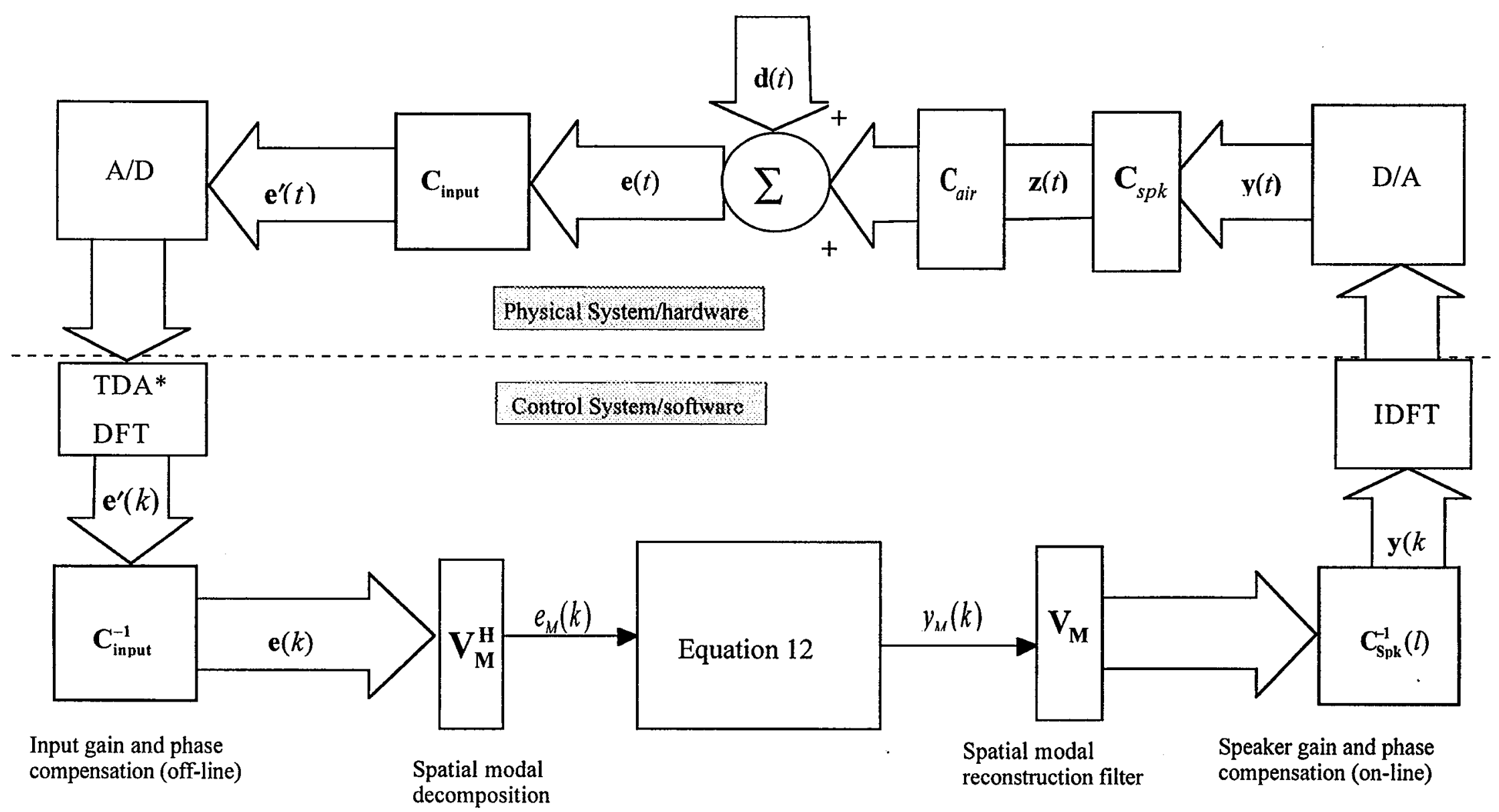

TDA: Time Domain Average

FIGURE 3. Modal Control System - Signal Flow Block Diagram 


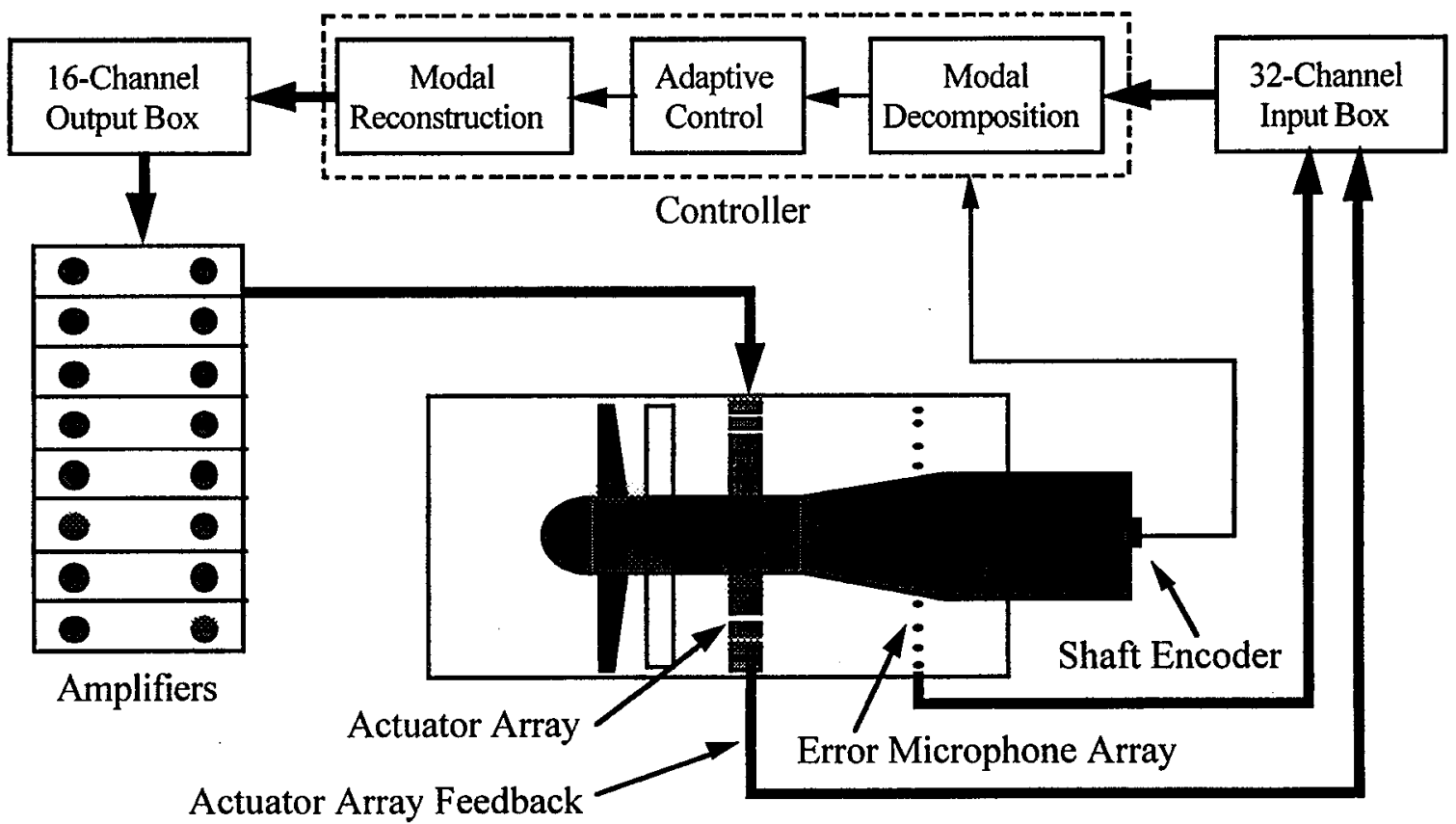

FIGURE 4. GE Active Noise Cancellation System Block Diagram as installed in NASA LeRC ANCF 


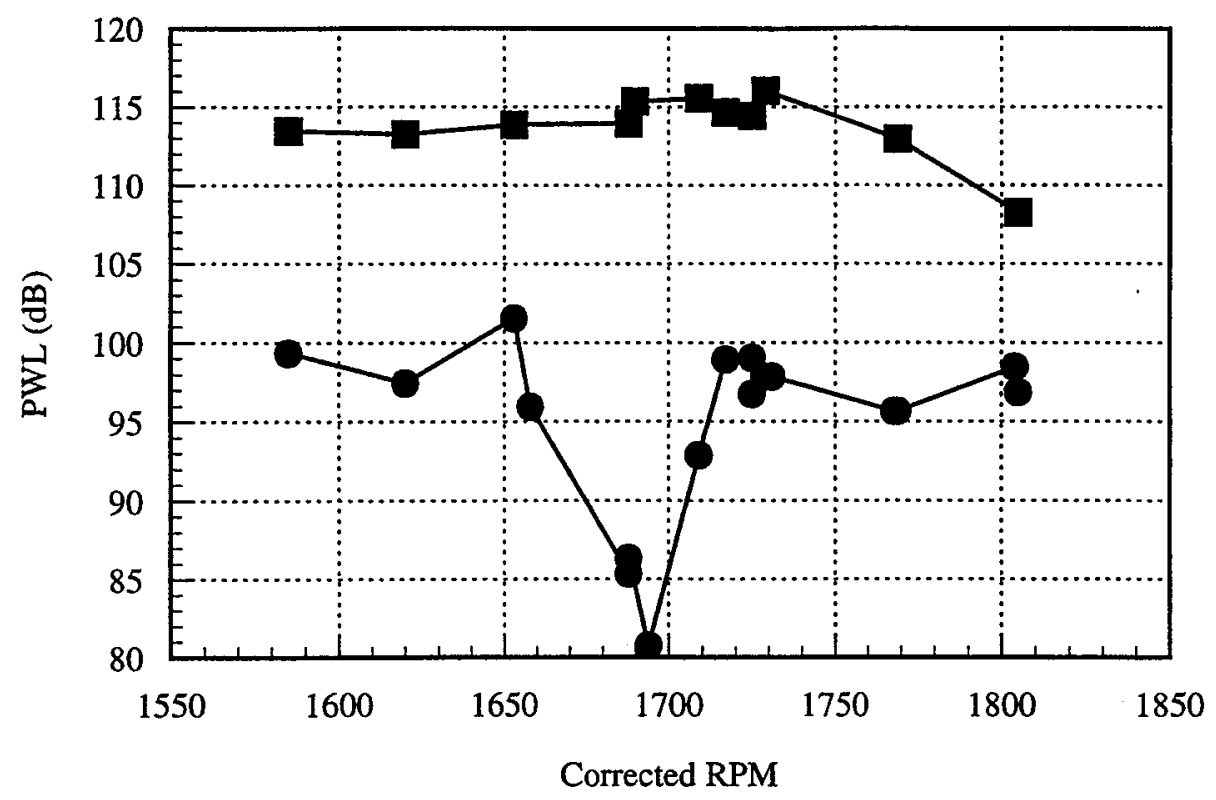

a) Mode (6,0) Power Levels in Exhaust

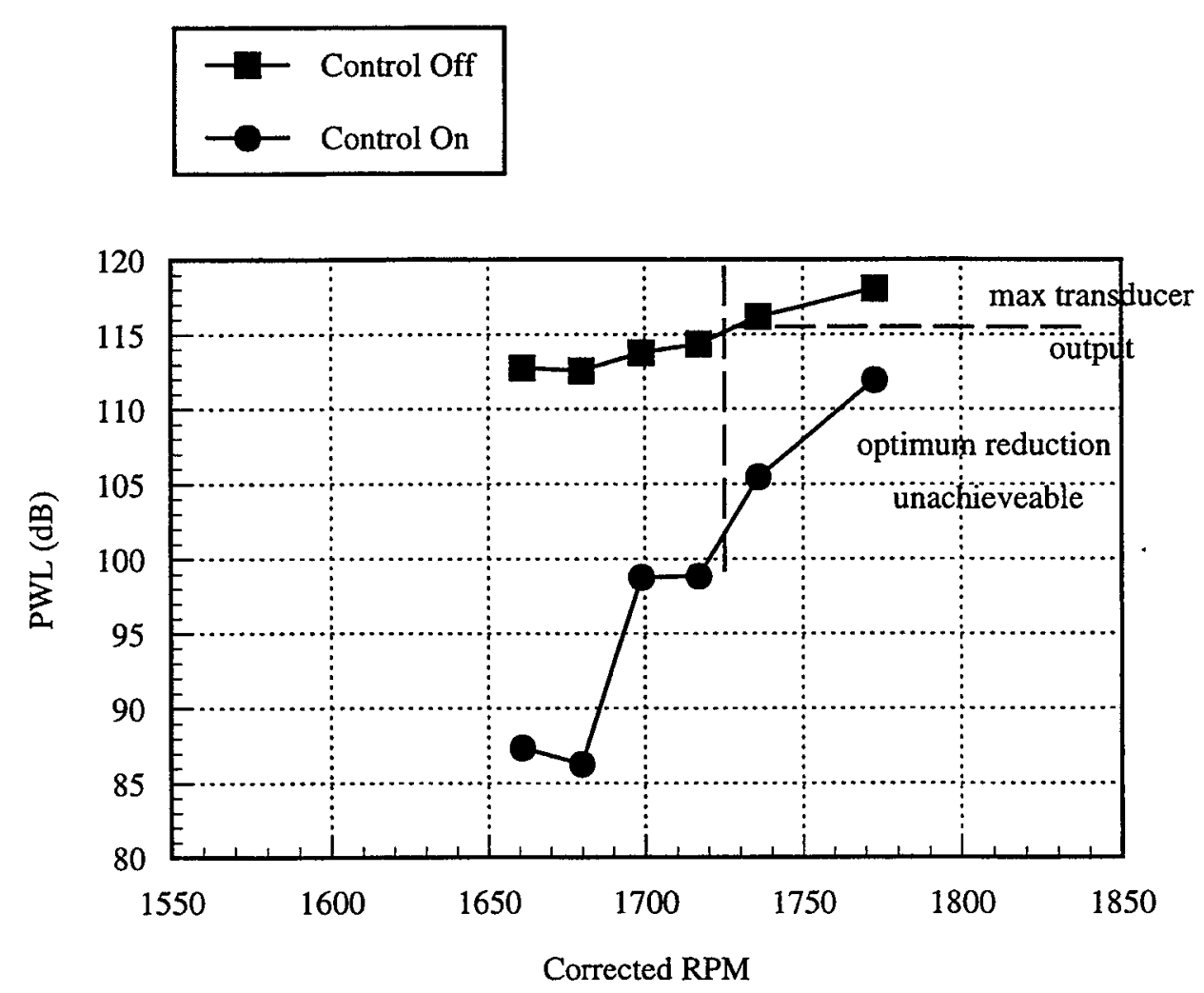

b) Mode (6,0) Power Levels in Inlet

FIGURE 5. Effect of ANC: Mode (6,0) PWL vs RPM 


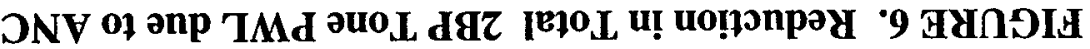

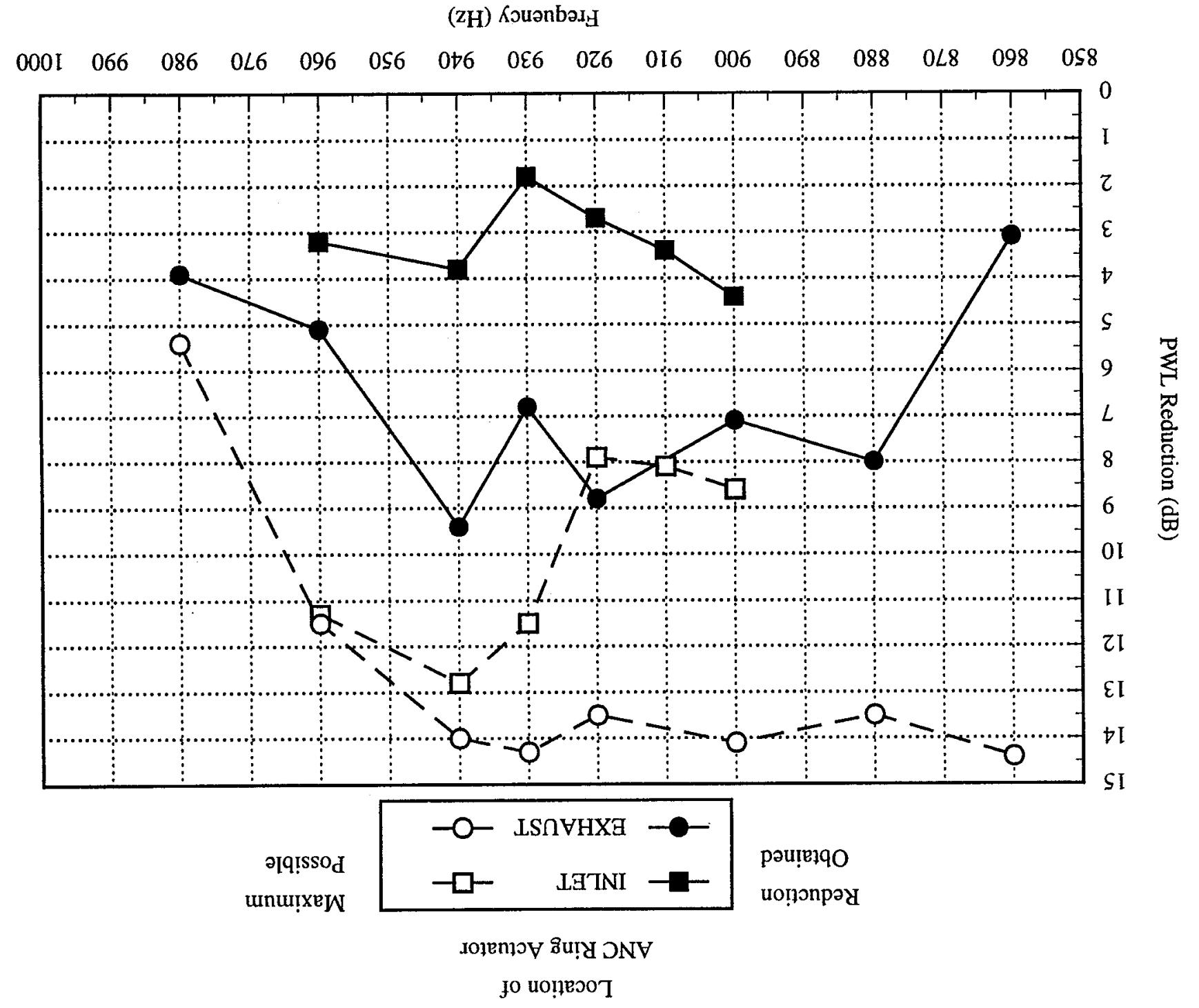



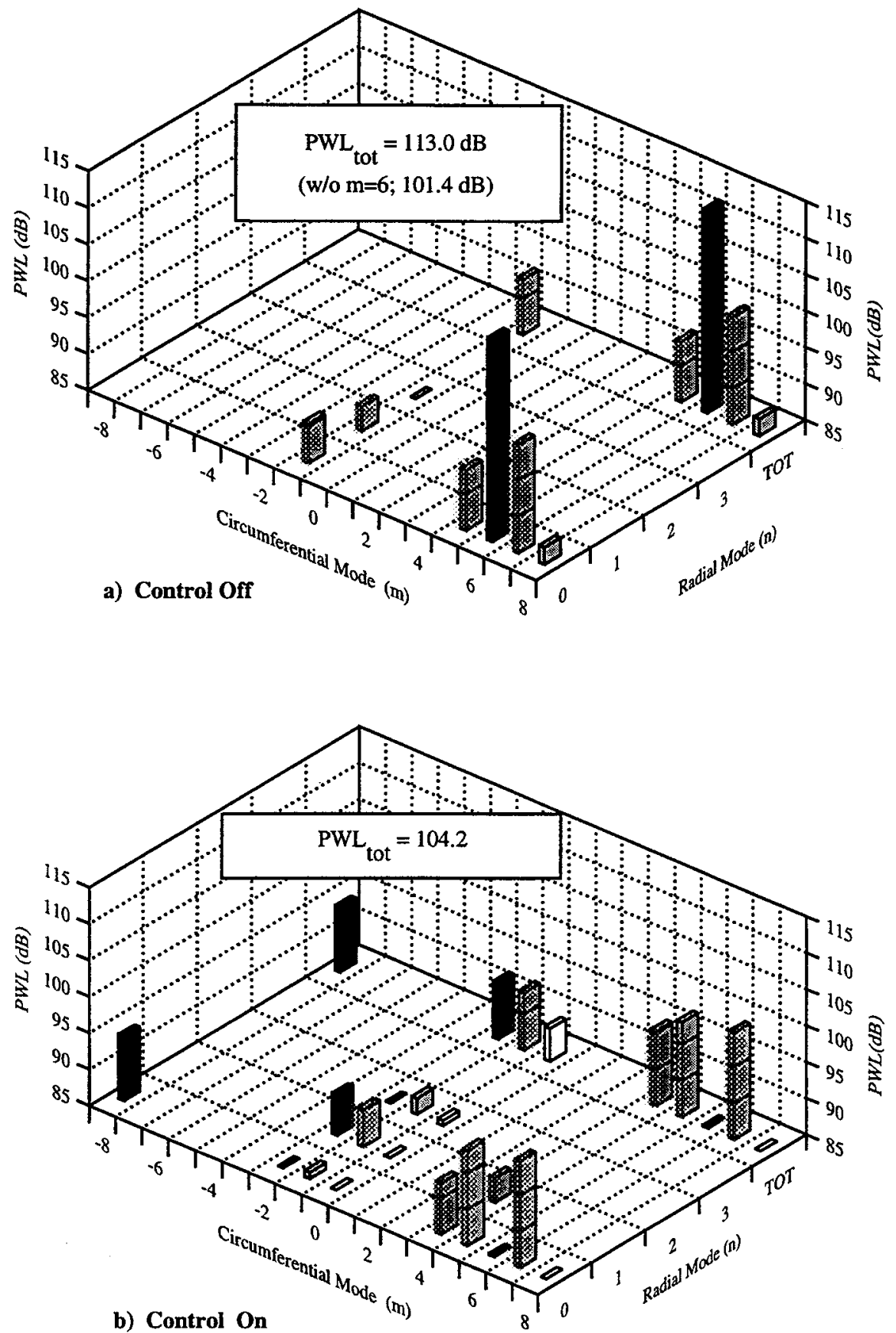

FIGURE 7. Modal Stucture Control Off/On with $m=6$ as ANC Target Exhaust, 2BPF, 1688 RPMc, $920 \mathrm{~Hz}$ (Low Modal Spillover) 



FIGURE 8. Modal Stucture Control Off/On with $m=6$ as ANC Target Exhaust, 2BPF, 1690 RPMc, $920 \mathrm{~Hz}$ (High Modal Spillover) 


$$
\begin{aligned}
& \mathrm{PWL}_{\text {tot }}=119.4 \mathrm{~dB} \\
& (\mathrm{w} / \mathrm{o} \mathrm{m}=6 ; 108.9 \mathrm{~dB})
\end{aligned}
$$

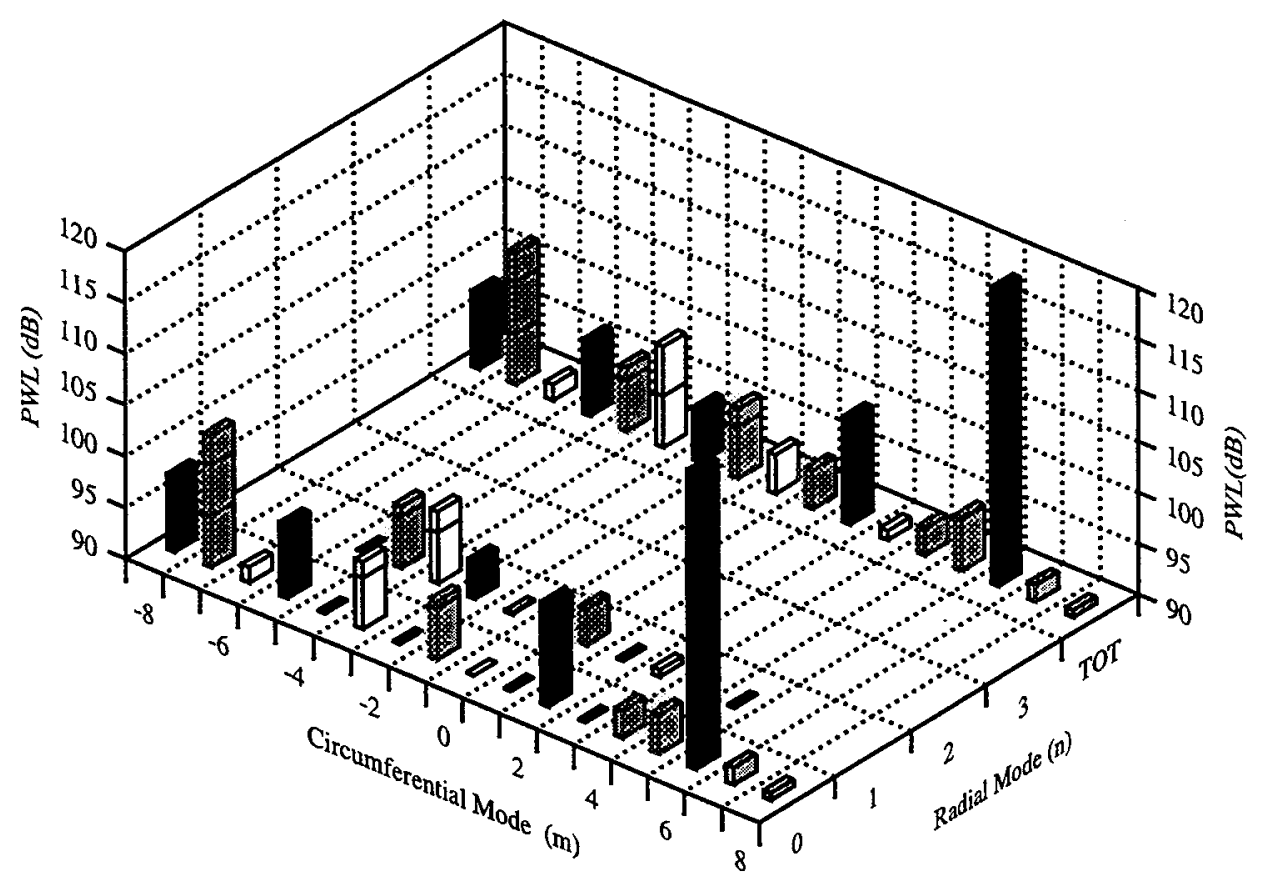

FIGURE 9. Modal Stucture Generated by ANC System with $\mathrm{m}=6$ Target Exhaust, 2BPF, Fan Off, $920 \mathrm{~Hz}$ 


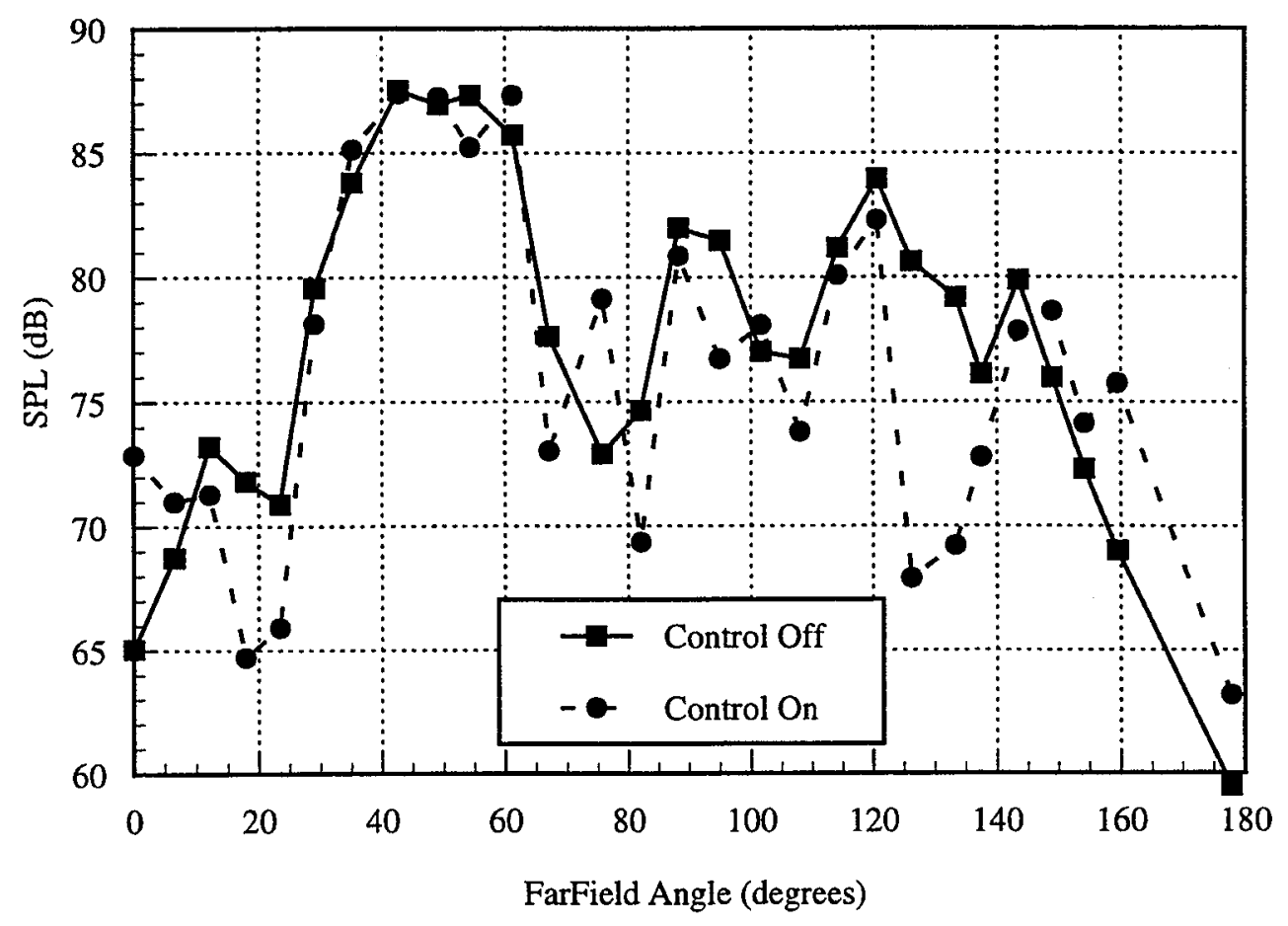

a) Absolute Farfield Levels

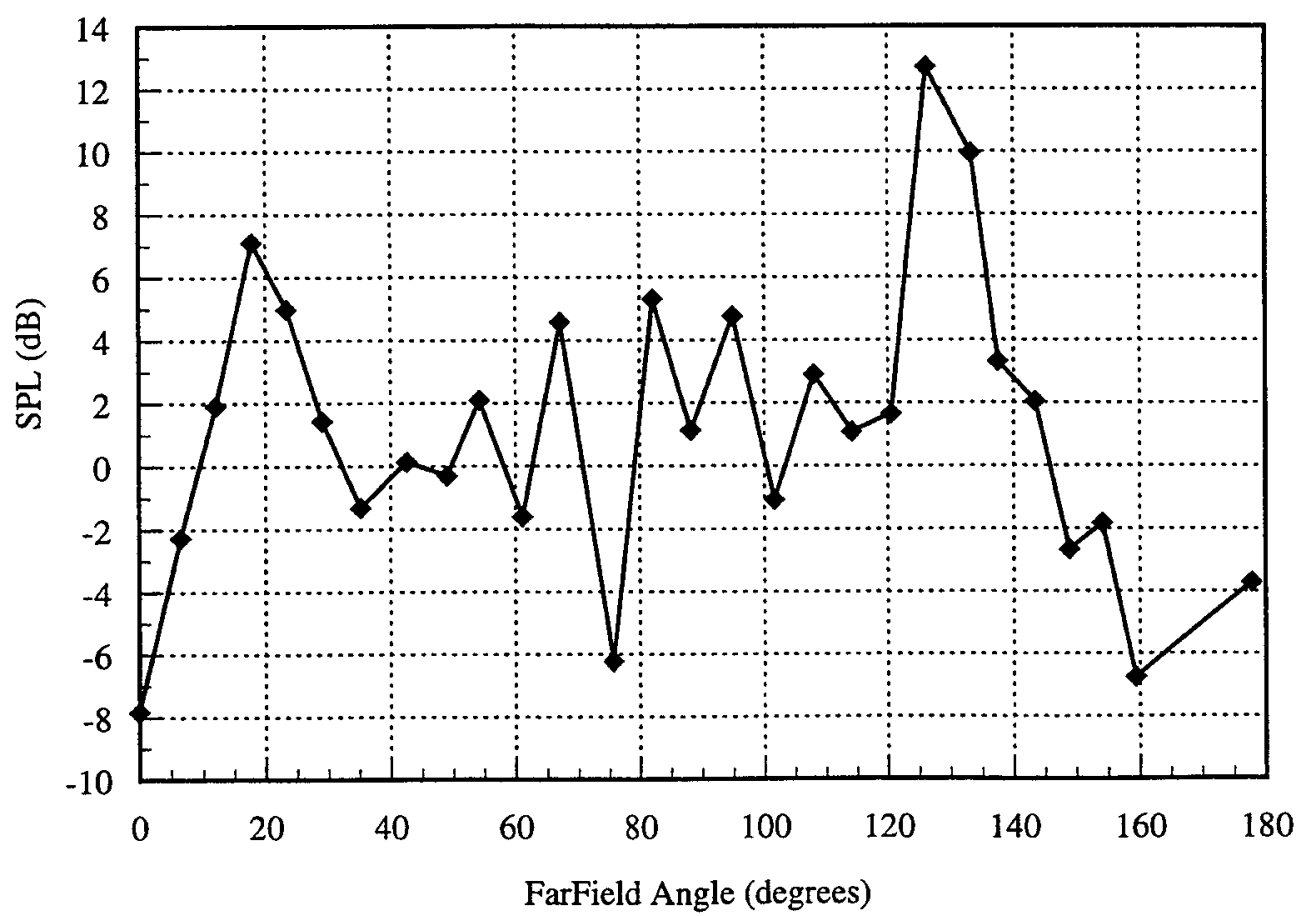

b) Reduction in Farfield SPL

FIGURE 10. Farfield SPL Directivity with ANC in Exhaust 


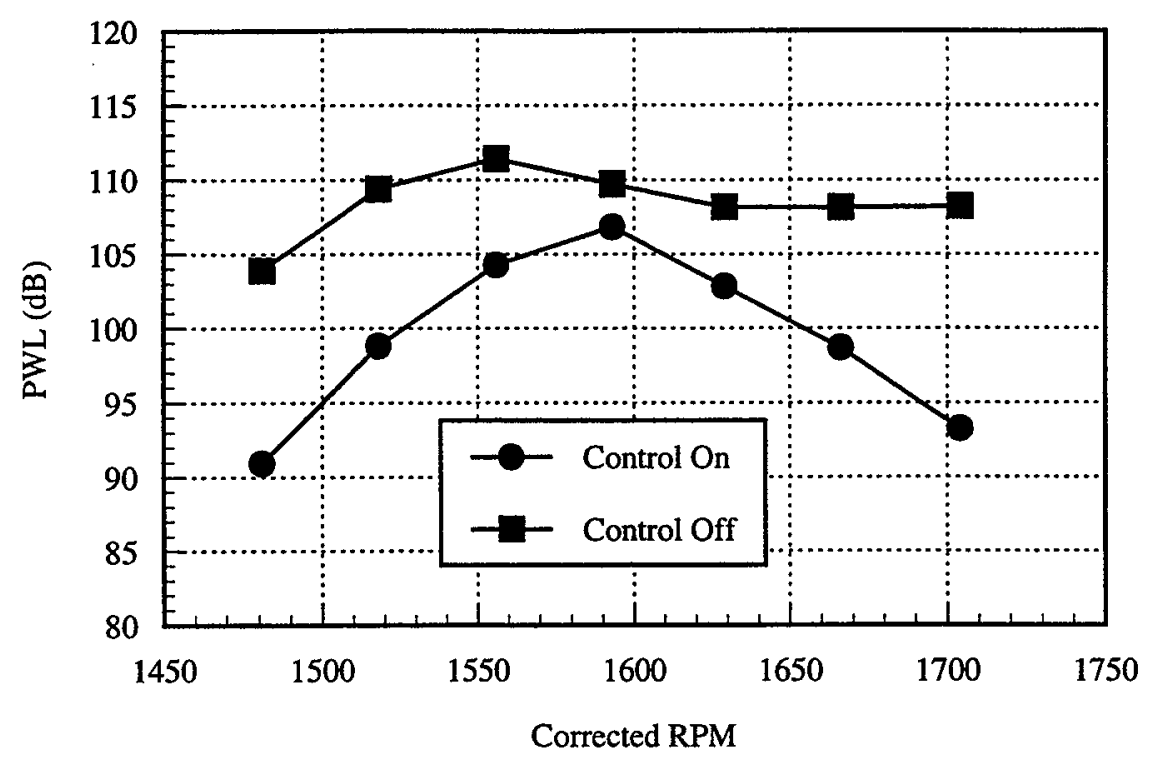

a) Mode $m=4$ Total

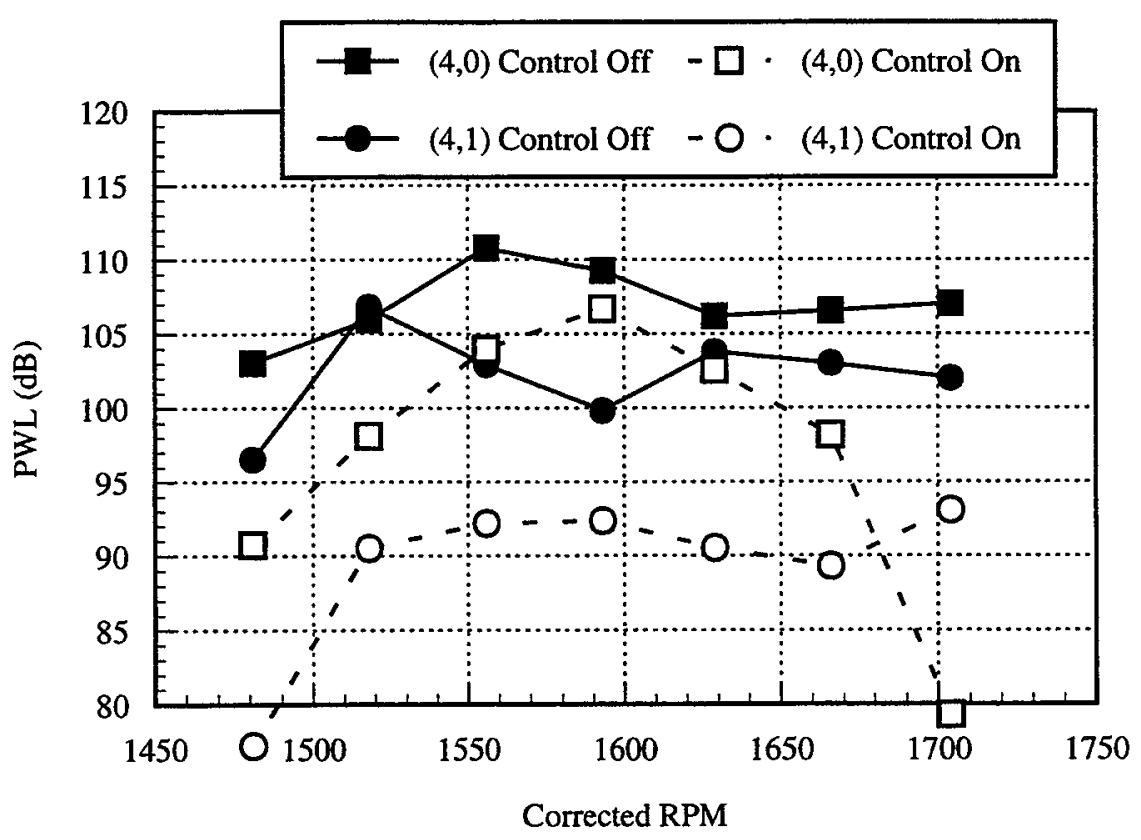

b) $(4,0) \&(4,1)$ Mode Levels

FIGURE 11. Effectiveness of ANC with 2 Radials in Duct Mode 4 PWL vs RPM 

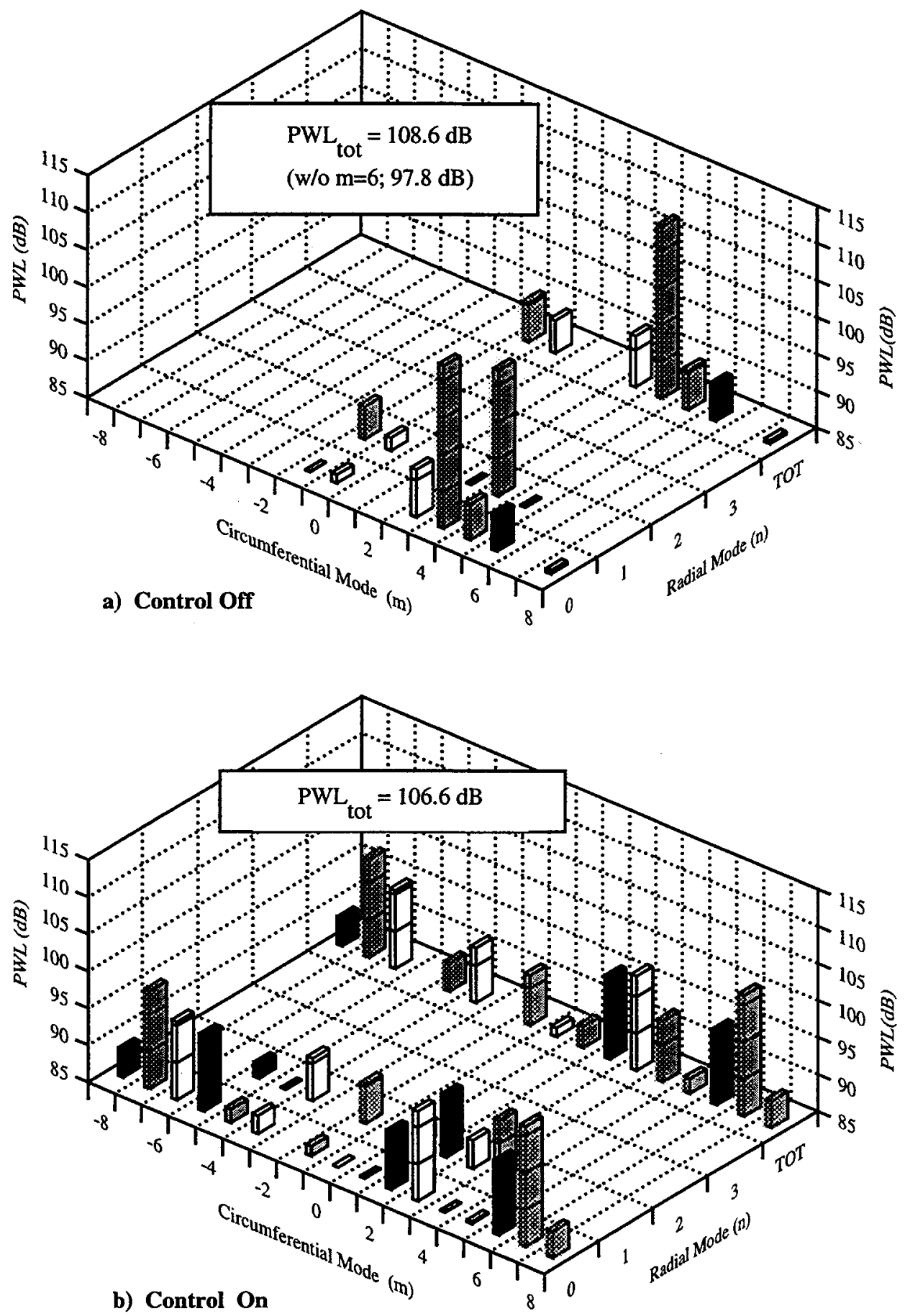

FIGURE 12. Modal Stucture Control Off/On with $m=4$ ANC Target Exhaust, 2BPF, 1704 RPMc, 920 Hz 


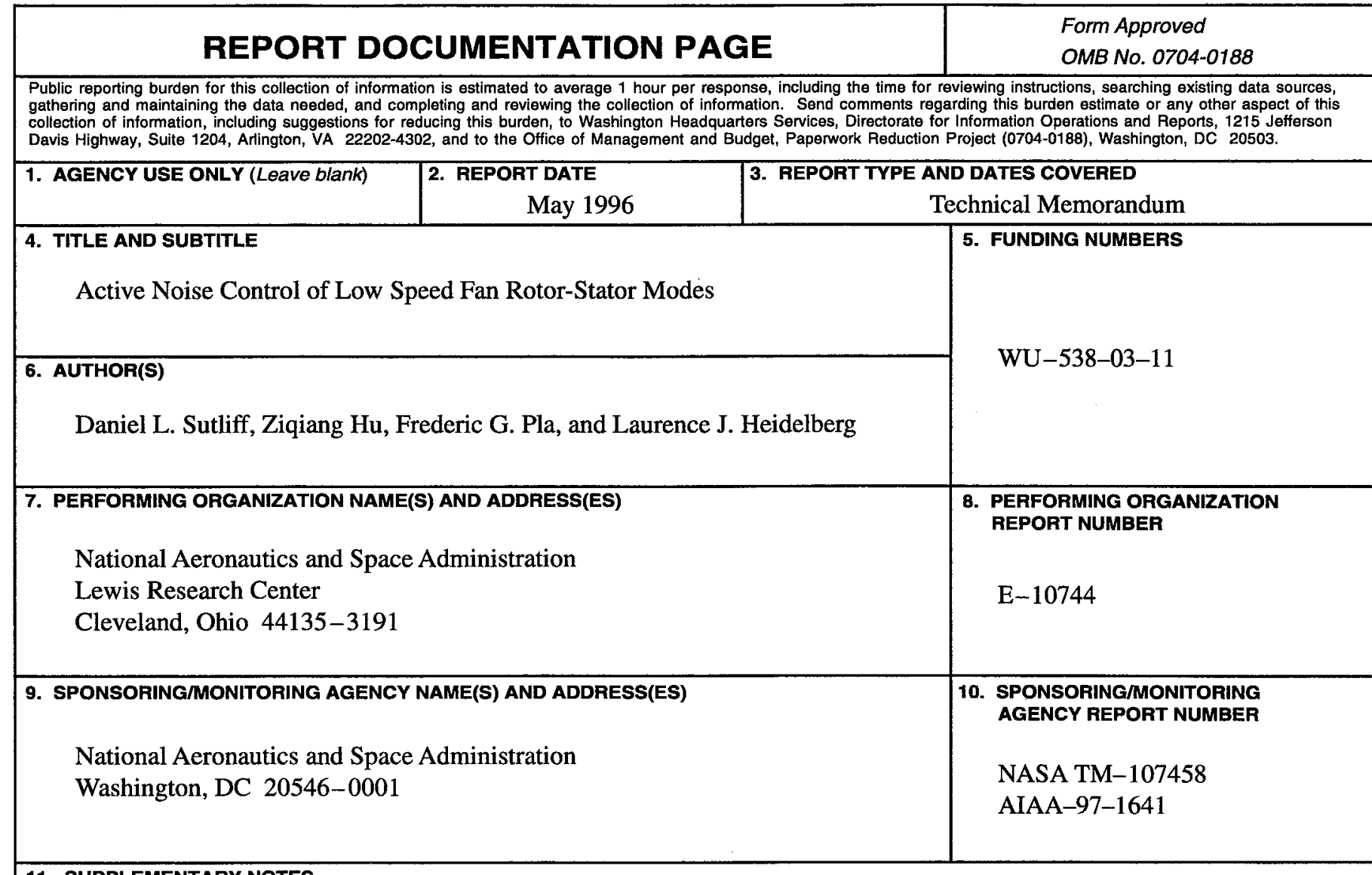

11. SUPPLEMENTARY NOTES

Prepared for the 3rd Aeroacoustic Conference cosponsored by the American Institute of Aeronautics and Astronautics and the Confederation of European Aerospace Societies, Atlanta, Georgia, May 12-14, 1997. Daniel L. Sutliff, AYT Corporation, 2001 Aerospace Parkway, Brook Park, Ohio 44142 (work funded by NASA Contract NAS3-27571); Ziqiang Hu and Frederic G. Pla, General Electric Corporate Research and Development Center, Schenectady, New York 12301; Laurence J. Heidelberg, NASA Lewis Research Center. Responsible person, Daniel L. Sutliff, organization code 5940, (216) 433-6290.

12a. DISTRIBUTION/AVAILABILITY STATEMENT 12b. DISTRIBUTION CODE

Unclassified - Unlimited

Subject Categories 07 and 71

This publication is available from the NASA Center for AeroSpace Information, (301) 621-0390.

13. ABSTRACT (Maximum 200 words)

This report describes the Active Noise Cancellation System designed by General Electric and tested in the NASA Lewis Research Center's 48 inch Active Noise Control Fan. The goal of this study was to assess the feasibility of using wall mounted secondary acoustic sources and sensors within the duct of a high bypass turbofan aircraft engine for active noise cancellation of fan tones. The control system is based on a modal control approach. A known acoustic mode propagating in the fan duct is canceled using an array of flush-mounted compact sound sources. Controller inputs are signals from a shaft encoder and a microphone array which senses the residual acoustic mode in the duct. The canceling modal signal is generated by a modal controller. The key results are that the $(6,0)$ mode was completely eliminated at $920 \mathrm{~Hz}$ and substantially reduced elsewhere. The total tone power was reduced $9.4 \mathrm{~dB}$. Farfield 2BPF SPL reductions of $13 \mathrm{~dB}$ were obtained. The $(4,0)$ and $(4,1)$ modes were reduced simultaneously yielding a $15 \mathrm{~dB}$ modal PWL decrease. Global attenuation of PWL was obtained using an actuator and sensor system totally contained within the duct.

14. SUBJECT TERMS

Ducted fans; Engine noise; Aircraft noise; Aeroacoustics; Active noise control

17. SECURITY CLASSIFICATION OF REPORT

Unclassified
18. SECURITY CLASSIFICATION OF THIS PAGE Unclassified
19. SECURITY CLASSIFICATION OF ABSTRACT Unclassified 